\title{
Hot workability of AISI 321 and AISI 304 austenitic stainless steels
}

\author{
Richard K.C. Nkhoma*, Charles W. Siyasiya and Waldo E. Stumpf, \\ Department of Materials Science and Metallurgical Engineering, University of Pretoria, 0002 Pretoria, South
} Africa.

*Corresponding author: Richard Nkhoma, e-mail: rnkhoma@gmail.com

\begin{abstract}
Although the austenitic stainless steels 304 and 321 are often treated nominally as equivalents in their hot rolling characteristics, the question remains whether any subtle differences between the two allow further optimisation of their respective hot rolling schedules. The hot workability of these two types of austenitic stainless steels were compared through single-hit Gleeble simulated thermomechanical processing between $800^{\circ} \mathrm{C}$ and $1200^{\circ} \mathrm{C}$ while the strain rate was varied between $0.001 / \mathrm{s}$ and $5 / \mathrm{s}$. It was found that the constants for the hyperbolic sine equation for hot working of 321 steel are $Q=465 \mathrm{~kJ} / \mathrm{mol}, \mathrm{A}_{3}=9.76 \times 10^{17} \mathrm{MPa}^{-1} s^{-1}$, $\alpha=0.009 \mathrm{MPa}^{-1}$ and $n=6.1$ while for 304 steel the constants are $Q=446 \mathrm{~kJ} / \mathrm{mol}$, $\mathrm{A}_{3}=2.14 . \times 10^{17} \mathrm{MPa}^{-1} s^{-1}, \alpha=0.008 \mathrm{MPa}^{-1}$ and $n=6.1$. It is shown that the occurrence of dynamic recrystallisation starts when the Zener Hollomon parameter $Z \approx 6.4 \times 10^{17}$ for both steels but that the differences in the values of $\mathrm{Q}$ and $\mathrm{A}_{3}$ (the structure factor) between the two steels does lead to consistently lower steady state stresses for the steel 321 than is found in the steel 304 at the same $\mathrm{Z}$ values. This may, therefore, offer some scope for further optimisation of the hot rolling schedules and in particular in the mill loads of these two respective steels.
\end{abstract}

Key words: dynamic recrystallisation (DRX), dynamic recovery (DRV), AISI 321. 


\subsection{Introduction}

The issue of low proof stress values at room temperature for the standard austenitic stainless steels has been plaguing the steel manufacturing industry for many years. Type 321 stainless steel has nominally the same chemical composition as type 304 steel (see table 2.1) with the only major difference being the addition of titanium to the former for stabilisation of the carbon and nitrogen and also to improve the creep resistance of the steel. Carbon is in solution in 304 stainless steel while it is combined in 321 as $\mathrm{TiC}$ and $\mathrm{Ti}(\mathrm{CN})$ to avoid sensitisation and intergranular corrosion[1]. Consequently, 321 austenitic stainless steel generally suffers from both metallurgical defects from Ti-inclusions and low proof strength when compared to type 304 as the $\mathrm{C}$ is tied up in $\mathrm{TiC} / \mathrm{Ti}(\mathrm{CN})$.

Pickering[2] has shown the disparities in proof stress between these two steels where the proof stress values for 321 are perpetually lower than 304 steel with nitrogen at all testing temperatures included in his analysis.

The objectives of this study are to critically evaluate the hot working characteristics of type 304 and type 321 austenitic stainless steels and to predict the critical conditions for the transition point between dynamic recrystallisation and dynamic recovery in type 321 austenitic stainless while those of the 304 steel serve as a benchmark.

\subsection{Experimental Procedures}

The microstructures of the as-received 304 and 321 stainless steel are shown in figure 2.1 while table 2.1 shows the respective chemical compositions. Figure 2.1 shows that the 321 steel has relatively larger and banded grain structure whereas the 304 steel has more deformation twins. Moreover 321 has more delta ferrite stringers that are running parallel to 
the rolling direction than 304 steel. The banding and the ferrite stringers made it difficult to determine the grain size for the 321 steel.
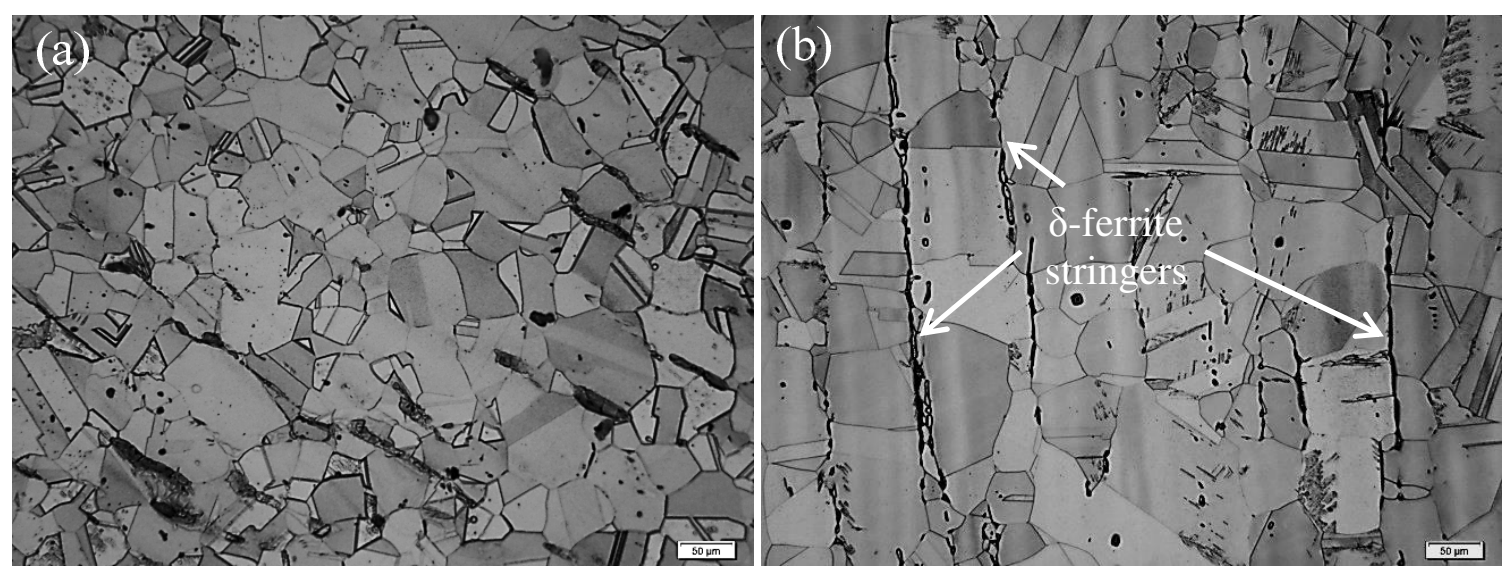

Figure 2.1: $\quad$ The as received steel's microstructures s (a) of the 304 steel and (b) the 321 steel.

Table 2.1: wt. \% composition of 321 and 304 steels

\begin{tabular}{lccccccccccccc}
\hline Steel & $\mathrm{C}$ & $\mathrm{Cr}$ & $\mathrm{Si}$ & $\mathrm{Mn}$ & $\mathrm{N}$ & $\mathrm{Ti}$ & $\mathrm{Al}$ & $\mathrm{B}$ & $\mathrm{Co}$ & $\mathrm{Cu}$ & $\mathrm{Ni}$ & $\mathrm{P}$ & $\mathrm{S}$ \\
\hline $\mathbf{3 2 1}$ & 0.027 & 17.13 & 0.59 & 1.08 & 0.0105 & 0.346 & 0.012 & 0.0003 & 0.09 & 0.12 & 9.11 & 0.021 & 0.0005 \\
$\mathbf{3 0 4}$ & 0.024 & 18.21 & 0.38 & 1.43 & 0.0725 & 0.001 & 0.003 & 0.0031 & 0.07 & 0.15 & 8.11 & 0.027 & 0.0023 \\
\hline
\end{tabular}

A servo-hydraulic thermomechanical Gleeble $1500^{\mathrm{TM}}$ hot work simulator with a specially constructed load cell fitted to the stationary part of the load train [3], was used in the single hit mode. The WC hot compression anvils were modified to an "isothermal mode" to minimise axial temperature gradients in the cylindrical samples of $10 \mathrm{~mm}$ diameter and 15 $\mathrm{mm}$ long that were machined from the rolling direction in both steels.

All tests followed the same pattern of heating as shown in figure 2.2 and each test was carried out under Argon to a total strain of about 1 but with varying strain rates. Initially the sample was heated to point $1 \mathrm{a} 4.2^{\circ} \mathrm{C} / \mathrm{s} \mathrm{t}$ and then held at that temperature for homogenisation up to point 2 from where the sample is heated to point 3 where it was soaked for 15 minutes before reducing to the deformation temperature in two stages with an average cooling rate of about $5.6^{\circ} \mathrm{C} / \mathrm{s}$. A thermal stabilisation time of $60 \mathrm{~s}$ was used before applying the deformation at 
respective strain rates of $0.001 s^{-1}, 0.01 s^{-1}, 0.1 s^{-1}, 1 s^{-1}$ and $5 s^{-1}$ for each deformation temperature starting from $1200^{\circ} \mathrm{C}$ to $800^{\circ} \mathrm{C}$ in reduction steps of $50^{\circ} \mathrm{C}$.

Tantalum foils were placed between the samples and the tungsten carbide anvils to reduce friction and to minimise barrelling (non-uniform deformation). A K-type thermocouple spot welded onto the specimen was used to measure and control the temperature.

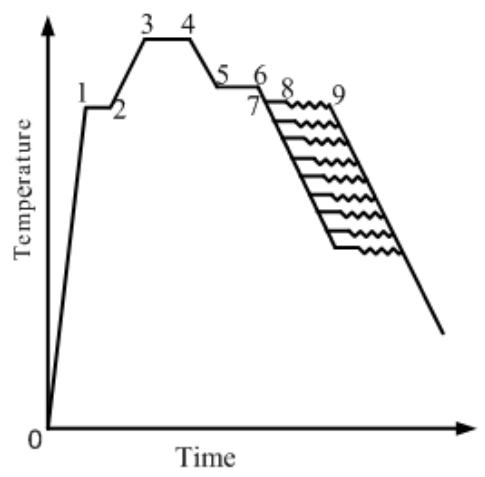

Figure 2.2: $\quad$ Schematic procedure for heating and deforming the samples in single hit tests.

The deformation data from the Gleeble was converted to true Von Mises flow stresses and strains [16] by using a corrective equation that takes into account the effect of friction between the pressure anvils and the samples[4]. A constant value of 0.1 for the coefficient of friction $\mu$ between the steel surface and the Ta foil, was used for all test temperatures as was also used by Uvira[5] for ferritic steels.

\subsection{Results}

Figure 3.1 shows typical stress-strain graphs for steel 321 for conditions that depict the microstructure undergoing DRV and DRX respectively. To determine the hot deformation constitutive parameters, the following equations were used[6-14].

$$
\begin{gathered}
Z=\dot{\epsilon} \exp \left(\frac{\mathrm{Q}}{\mathrm{RT}_{\mathrm{d}}}\right)=\mathrm{A} f(\sigma) \\
\epsilon_{p}=\mathrm{A}_{1} \mathrm{~d}_{\mathrm{o}}^{\mathrm{m}} \mathrm{Z}^{\mathrm{q}}
\end{gathered}
$$


where $\mathrm{Z}$ is the Zener-Hollomon parameter also known as the temperature compensated strain rate, $\dot{\varepsilon}$ is the strain rate, Q is the activation energy of hot working which is sometimes referred to as an (apparent) activation energy of deformation, $\mathrm{R}$ is the universal gas constant $\left(8.314 \mathrm{Jmol}^{-1} \mathrm{~K}^{-1}\right), \mathrm{T}_{\mathrm{d}}$ is the absolute deformation temperature, $\mathrm{A}_{1}, \mathrm{~m}$, and $\mathrm{q}$ are constants, $\mathrm{d}_{\mathrm{o}}$ is the initial grain size, $\epsilon_{\mathrm{p}}$ is the peak strain, $\mathrm{A}$ is the material constant which
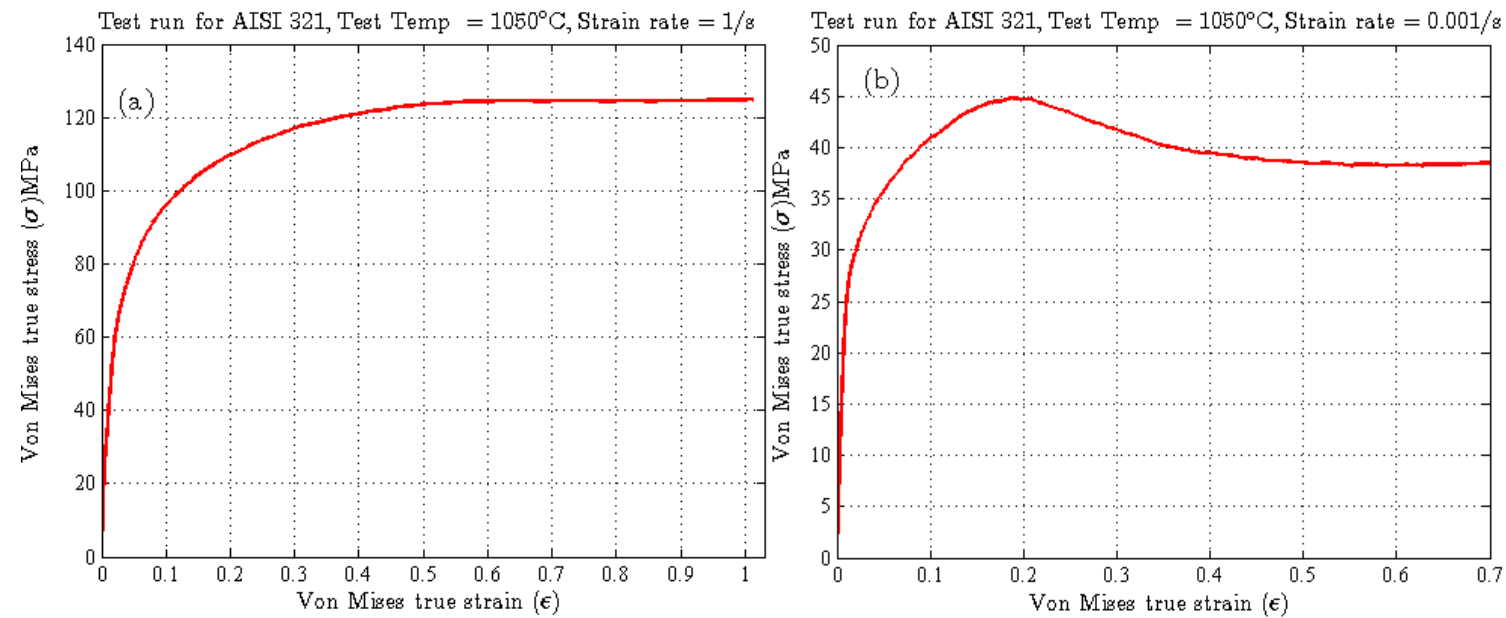

Figure 3.1: $\quad$ Stress - strain curves from hot compression tests at $1050^{\circ} \mathrm{C}$ for 321 steel, (a) for DRV at a strain rate of $1 / \mathrm{s}$ and (b) for DRX at a strain rate of $0.001 / \mathrm{s}$.

depends on the initial austenite grain size and chemical composition of the material [15] and $f(\sigma)$, is the stress function which has the following three forms [16][17]:

$$
\begin{aligned}
& Z=\dot{\epsilon} \exp \left(\frac{\mathrm{Q}}{\mathrm{RT}_{\mathrm{d}}}\right)=\mathrm{A} \sigma_{p}^{n^{\prime}} \\
& Z=\dot{\epsilon} \exp \left(\frac{\mathrm{Q}}{\mathrm{RT}_{\mathrm{d}}}\right)=\mathrm{A}_{2} \exp \left(\beta \sigma_{0}\right) \\
& Z=\dot{\epsilon} \exp \left(\frac{\mathrm{Q}}{\mathrm{RT}_{\mathrm{d}}}\right)=\mathrm{A}_{3}\left[\sinh \left(\alpha \sigma_{p}\right)\right]^{n}
\end{aligned}
$$

where $\beta$ is a constant, $\alpha$ is the material constant and can be calculated from $\alpha=\beta / n^{\prime}, \sigma_{p}$ is the peak flow stress which is obtained directly from the flow stress-strain curves and $n$ is the stress sensitivity constant. The steady state flow stress $\sigma_{s s}$, is sometimes used instead of 
$\sigma_{p}$ as this makes the $\mathrm{Z}$ value independent of strain. Generally, equation [3-3] is used for low stress calculations while equation [3.-4] is used for high stress calculations. The hyperbolic

Table 3.1: equations used in order to find the constitutive constants

\begin{tabular}{|c|c|c|c|c|c|}
\hline Cst & Equations used & Hold & Vary & What to plot? & Figures \\
\hline$n^{\prime}$ & $\begin{array}{c}\ln \dot{\epsilon}+\frac{\mathrm{Q}}{\mathrm{RT}_{\mathrm{d}}}=\ln \mathrm{A}+n^{\prime} \ln \sigma_{p} \\
n^{\prime}=\frac{\partial \ln \dot{\epsilon}}{\partial \ln \sigma_{p}}\end{array}$ & $\mathrm{~T}_{\mathrm{d}}$ & $\dot{\epsilon}$ & $\ln \dot{\epsilon} v s \ln \sigma_{p}$ & $\begin{array}{l}\text { figure } \\
3.3(\mathrm{a})\end{array}$ \\
\hline$\beta$ & $\begin{array}{c}\ln \dot{\epsilon}+\frac{\mathrm{Q}}{\mathrm{RT}_{\mathrm{d}}}=\ln \mathrm{A}_{2}+\beta \sigma_{p} \\
\beta=\frac{\partial \ln \dot{\epsilon}}{\sigma_{p}}\end{array}$ & $\mathrm{~T}_{\mathrm{d}}$ & $\dot{\epsilon}$ & $\ln \dot{\epsilon} v s \sigma_{p}$ & $\begin{array}{l}\text { figure } \\
3.3(b)\end{array}$ \\
\hline$\alpha$ & $\alpha=\beta / n^{\prime}$ & - & - & - & - \\
\hline $\mathrm{A}_{3}$ & $\begin{array}{l}\mathrm{Z}=\dot{\epsilon} \exp \left(\frac{\mathrm{Q}}{\mathrm{RT}_{\mathrm{d}}}\right)=\mathrm{A}_{3}\left[\sinh \left(\alpha \sigma_{p}\right)\right]^{n} \\
\ln \epsilon=\ln A_{3}+n \ln \left[\sinh \left(\alpha \sigma_{p}\right)\right]-\frac{Q}{R T_{d}}\end{array}$ & - & - & $\ln Z v s \ln \left[\sinh \left(\alpha \sigma_{p}\right)\right]$ & $\begin{array}{l}\text { figure } \\
3.5(\mathrm{a})\end{array}$ \\
\hline $\mathrm{A}_{1} \mathrm{~d}_{\mathrm{o}}^{\mathrm{m}}$ & $\epsilon_{p}=\mathrm{A}_{1} \mathrm{~d}_{0}^{\mathrm{m}} \mathrm{Z}^{\mathrm{q}}$ & - & - & $\ln \epsilon_{p} v s \ln Z$ & $\begin{array}{c}\text { figure } \\
3.5(\mathrm{~b} \& \mathrm{c})\end{array}$ \\
\hline Q & $\begin{array}{c}\ln \epsilon^{\cdot}=\ln A_{3}+n \ln \left[\sinh \left(\alpha \sigma_{p}\right)\right]-\frac{Q}{R T_{d}} \\
\mathrm{Q}=n \mathrm{R} \frac{\partial \ln \left\{\left[\sinh \left(\alpha \sigma_{p}\right)\right]\right\}}{\partial\left(1 / T_{d}\right)}\end{array}$ & $\dot{\epsilon}$ & $\mathrm{T}_{\mathrm{d}}$ & $\begin{array}{l}\ln \left[\sinh \left(\alpha \sigma_{p}\right)\right] v s 1 / T \\
\ln \sigma_{p} v s 1 / T \\
\sigma_{p} v s 1 / T\end{array}$ & $\begin{array}{l}\text { figure } \\
3.3(\mathrm{~d}) \\
\text { figure } \\
3.4(\mathrm{a}) \\
\text { figure } \\
\text { 3.4(b) }\end{array}$ \\
\hline$q$ & $\epsilon_{p}=\mathrm{A}_{1} \mathrm{~d}_{0}^{\mathrm{m}} \mathrm{Z}^{\mathrm{q}}$ & - & - & $\ln \epsilon_{p} v s \ln Z$ & $\begin{array}{c}\text { figure } \\
3.5(\mathrm{~b} \& \mathrm{c})\end{array}$ \\
\hline$n$ & $\begin{array}{c}\ln \dot{\epsilon}=\ln A_{3}+n \ln \left[\sinh \left(\alpha \sigma_{p}\right)\right]-\frac{Q}{R T_{d}} \\
n=\frac{\partial \ln \dot{\epsilon}}{\partial \ln \left\{\left[\sinh \left(\alpha \sigma_{p}\right)\right]\right\}}\end{array}$ & $\mathrm{T}_{\mathrm{d}}$ & $\dot{\epsilon}$ & $\ln Z v s \ln \left[\sinh \left(\alpha \sigma_{p}\right)\right]$ & $\begin{array}{l}\text { figure } \\
3.3(\mathrm{c}) \\
\text { figure } \\
3.5(\mathrm{a} \& \mathrm{c})\end{array}$ \\
\hline$\sigma_{c}$ & $\sigma_{c}=a \sigma_{p}$ & - & - & $\ln \sigma v s \ln Z$ & $\begin{array}{l}\text { figure } 3.7 \\
\& 3.8\end{array}$ \\
\hline$\epsilon_{c}$ & $\epsilon_{c}=b \epsilon_{p}$ & - & - & $\ln \epsilon v s \ln Z$ & $\begin{array}{ll}\text { figure } & 3.7 \\
\& 3.8 & \end{array}$ \\
\hline
\end{tabular}


sine equation [3-5] was proposed by Sellars and Tegart [21] to cover both stress regimes. When $\alpha \sigma \leq 0.8$, the test is considered to fall into the low stress regime while when $\alpha \sigma \geq 1.2$, the high stress regime is assumed. Taking natural logarithms on both sides of equations [3-3] to [3-5] and using partial differentiation, various relationships can be obtained as explained by others [6-14] and these relationships are tabulated in table 3.1 .

When all the data points are plotted by taking the natural logs of equation [3-2], the profile of the plots is shown in figure 3.5(b). It was observed that two regions are found, i.e. one region where DRX takes place and the other region where DRV occurs.
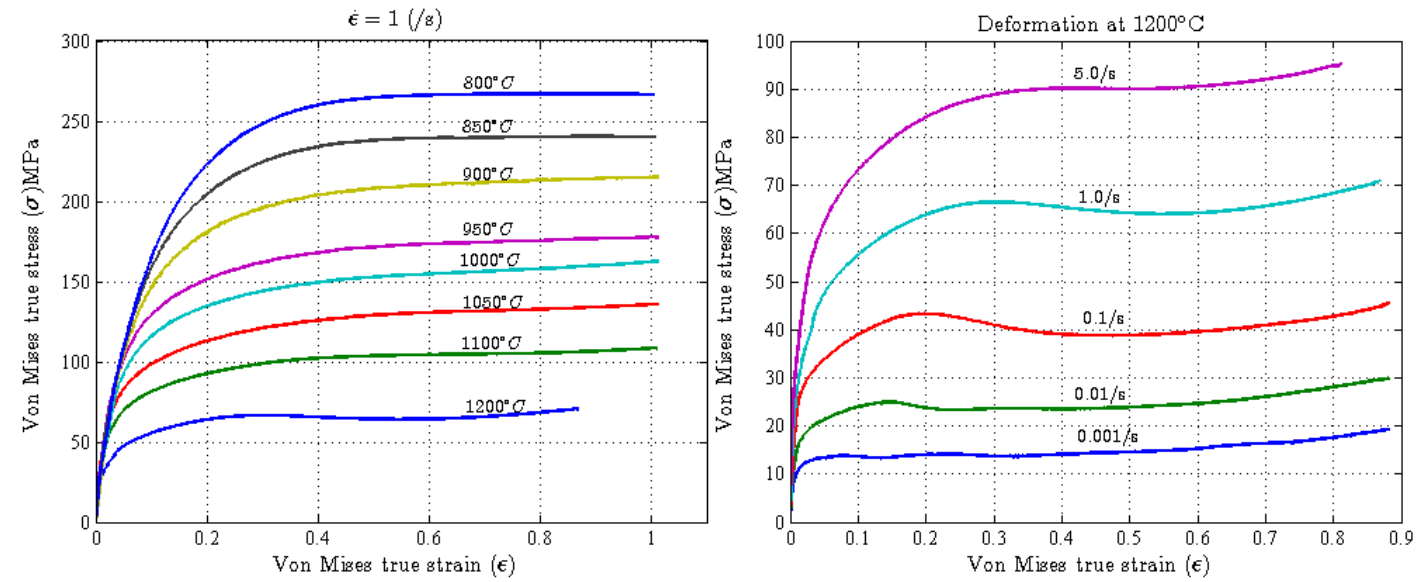

Figure 3.2: $\quad$ Typical flow stress curves at various deformation temperatures and strain rates for the 321 steel
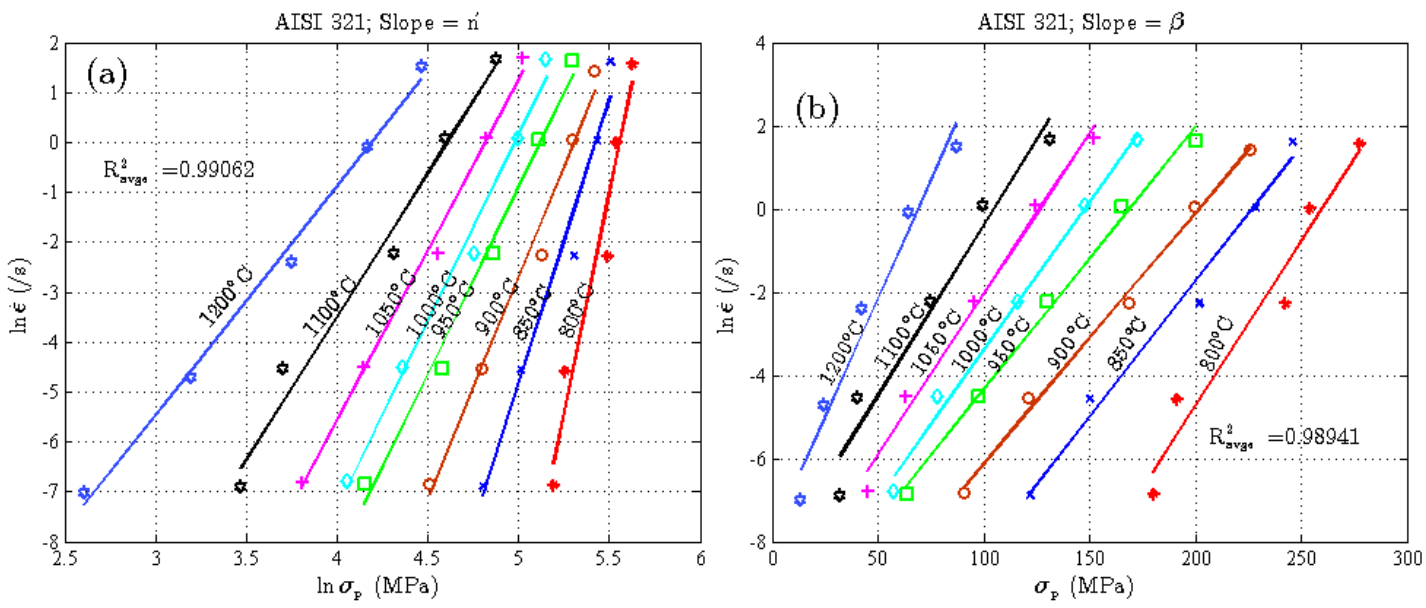

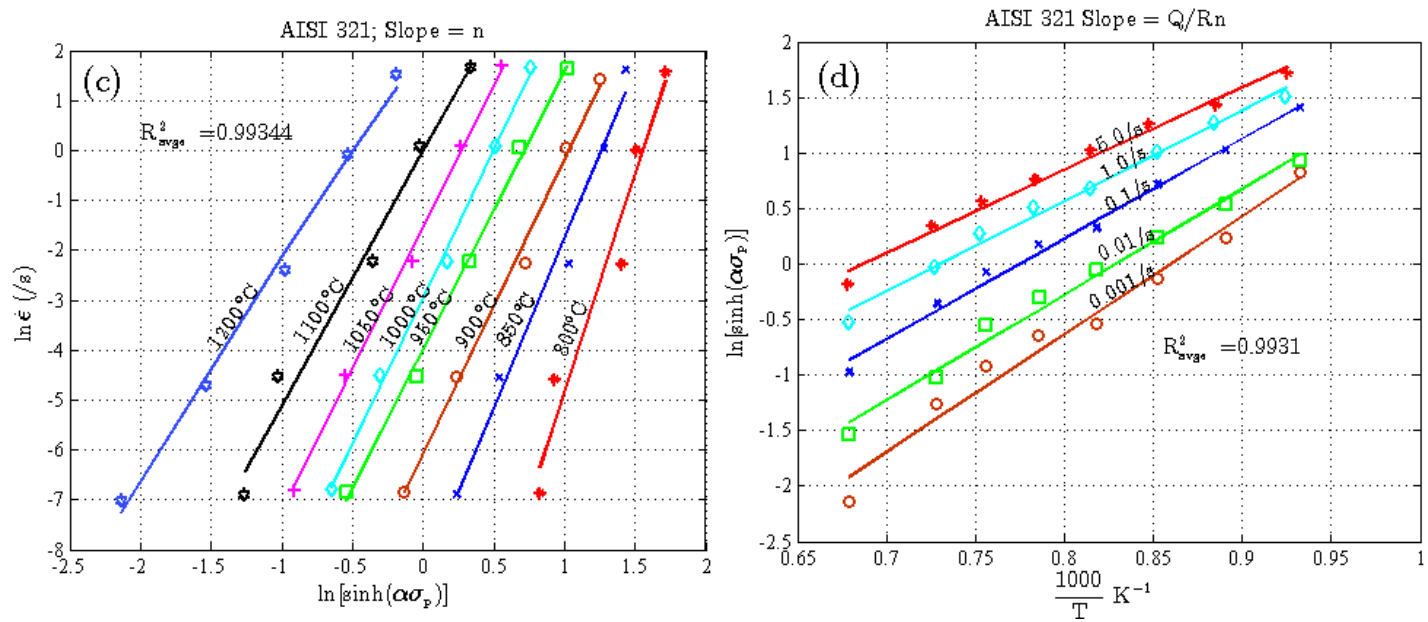

Figure 3.3: $\quad$ The determination of $n^{\prime}, \beta, n$ and $Q$ values for the 321 steel

These two regions are approximated by the straight lines as shown in figure 3.5(b) with the horizontal line depicting the DRV region while the sloping line depicts the DRX region. A point of interest is where the transition from DRX to DRV occurs as DRX will result in some grain refinement with grains having relatively low dislocation content while DRV will not introduce grain refinement but will introduce subgrains with high dislocation content in the cell walls. DRV in this case will, therefore, result if hot rolling is done where $\ln Z \geq 41$ (with
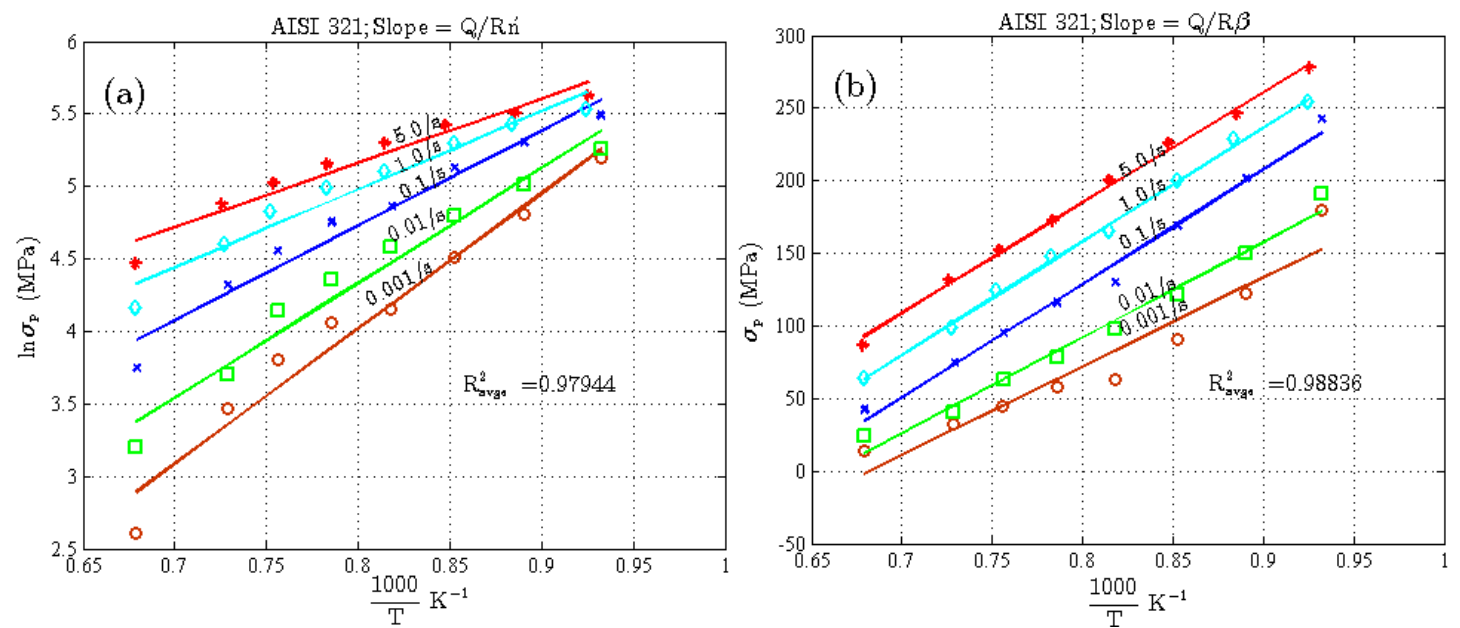

Figure 3.4:

The determination of $Q$ values for the 321 steel

$\mathrm{Z}_{\text {in }} \mathrm{s}^{-1}$ ) while at $\ln \mathrm{Z} \leq 41 \mathrm{DRX}$ and its associated material properties will result. Above the transition point, $\ln \epsilon_{p}$ is independent of $\ln Z$ and an observation from the individual flow 
stress graphs shows that this occurs when $0.4 \geq \epsilon_{p} \geq 0.5$ for the friction compensated flow profiles. So far, this transition region can be viewed as a $f\left(T_{d}, \dot{\epsilon}\right)$ as the calculations of $\ln Z$ were based on these parameters.
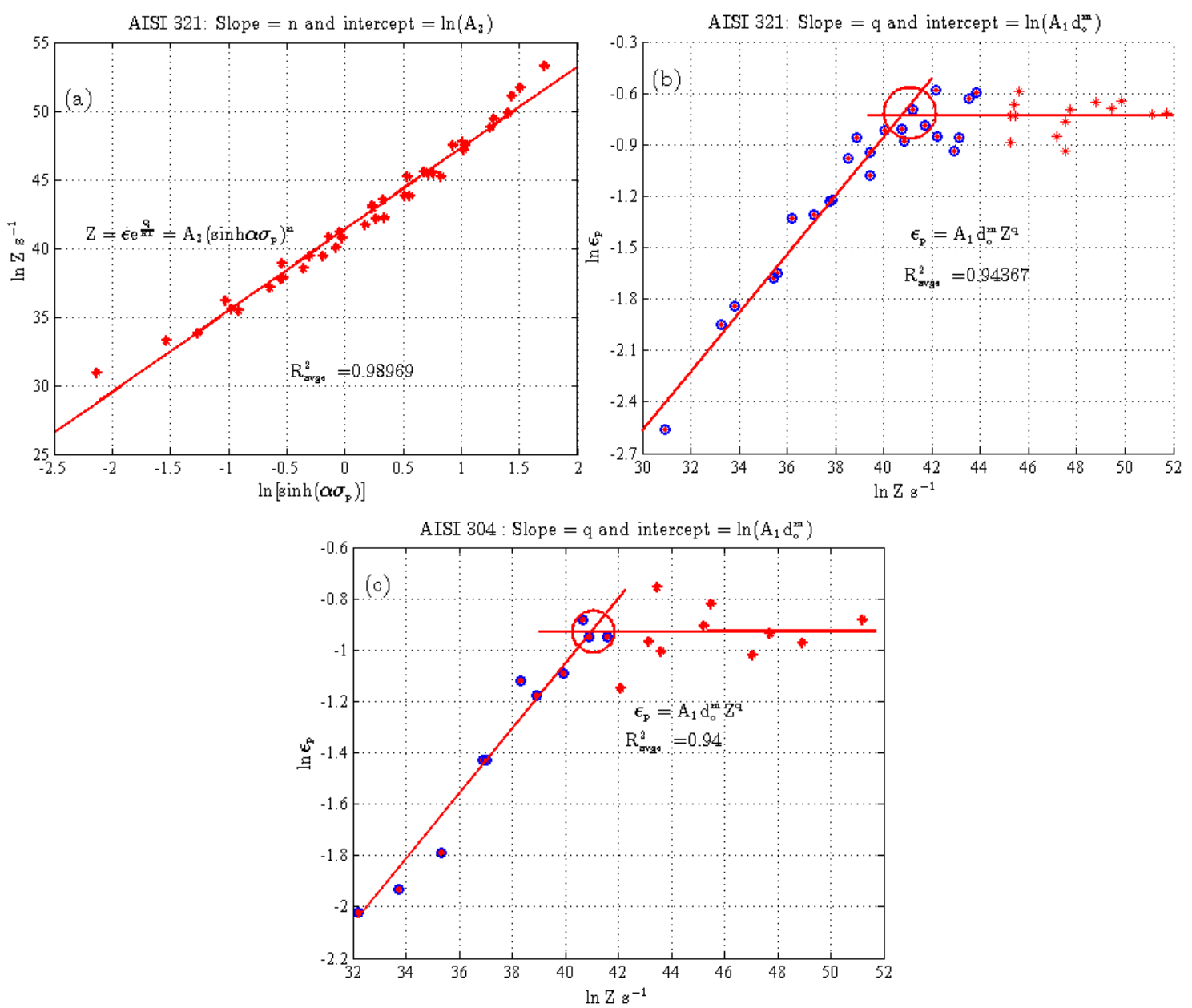

Figure 3.5: $\quad$ The determination of $n, A_{1}, A_{3}$ and $q$ values for (a and b) 321 steel and (c) 304 steel. The slope and intercept mentioned in (b) and (c) titles refer to the DRX (slanting) line and not the DRV (horizontal) line.

\subsection{Modelling the $\epsilon_{c} / \epsilon_{p}$ and $\sigma_{c} / \sigma_{p}$ ratios}

The critical strain and critical stress for the initiation of DRX can be analysed using either direct microstructural observations or from analysis of the flow stress curve profiles. The basic principle is that for DRX to be initiated, the local dislocation density must be high enough to allow new grains to nucleate and grow during deformation. The point at which this 
occurs corresponds to the critical strain $\left(\epsilon_{c}\right)$. It has been shown [18] that typically the initiation of DRX is preceded by growing fluctuations of grain boundary shape (serrations and bulges develop) prior to the new grains forming along these grain boundaries. Once the grain boundaries have been consumed by these 'new' grains the recrystallisation process will continue via nucleation at the interface between the recrystallised and non-recrystallised material. These two parameters (critical strain and stress) are significant for the prediction of the initiation of DRX as the operating restoration mechanism in hot working processes. Critical strain and critical stress values are attained in the flow stress profiles that show a peak first before lowering to the steady state [19]. In view of this, only flow stress profiles that clearly showed occurrences of DRX were used to find the relationship between critical stress and peak strain as well as the relationship between critical strain and peak strain. Because of "noise" in the signal, the data was first filtered and then approximated by a $9^{\text {th }}$ order polynomial of the plots which were shown to then fall on top of the original curve.
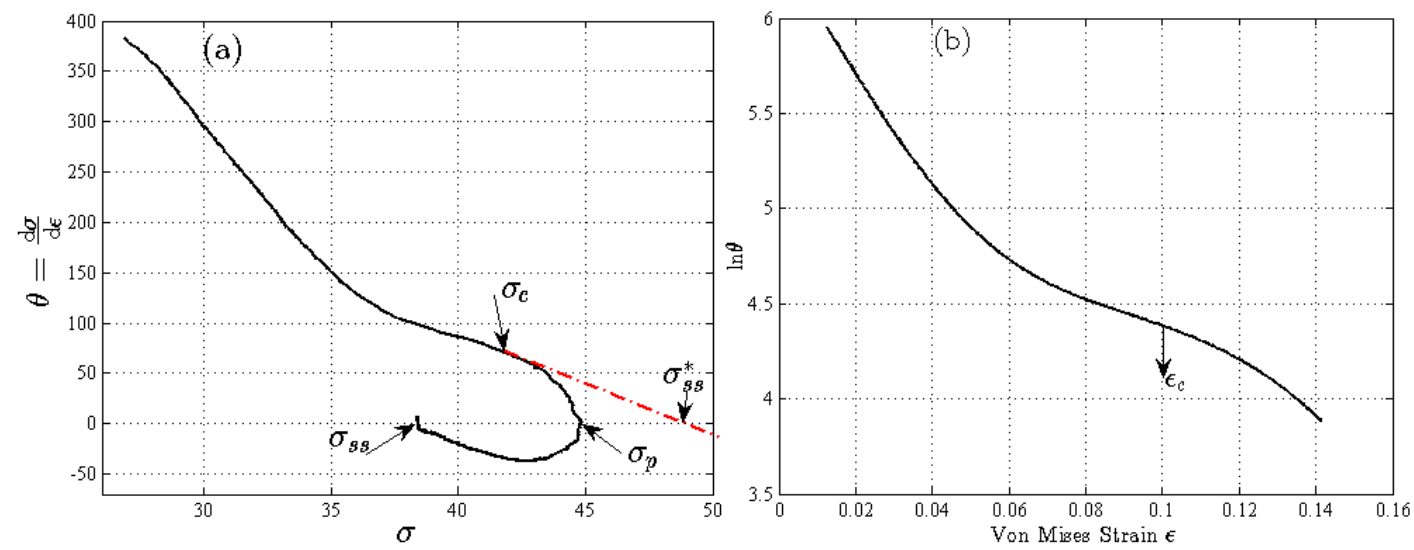

Figure 3.6: Stain hardening rate plots for 321 steel indicating how to find the (a) critical stress and (b) the critical strain values.

Then the approximated profile was differentiated and the results plotted as shown in figure 3.6 where the work hardening rate $(\theta)$ was plotted versus the Von Mises stress $(\sigma)$ and 
$\ln \theta$ was plotted versus the Von Mises strain $(\epsilon)$. The critical stress and strain values were then read off from the point of inflection as indicated by arrows on the graphs.

The $\sigma_{c}$ and $\epsilon_{c}$ values were plotted with their respective $\sigma_{p}$ and $\epsilon_{p}$ values versus $\ln Z$ as shown in figure 3.7 below and the following relationships were found for 321 austenitic stainless steel:

$$
\begin{aligned}
& \sigma_{c}=0.88 \sigma_{p} \\
& \epsilon_{c}=0.69 \epsilon_{p}
\end{aligned}
$$

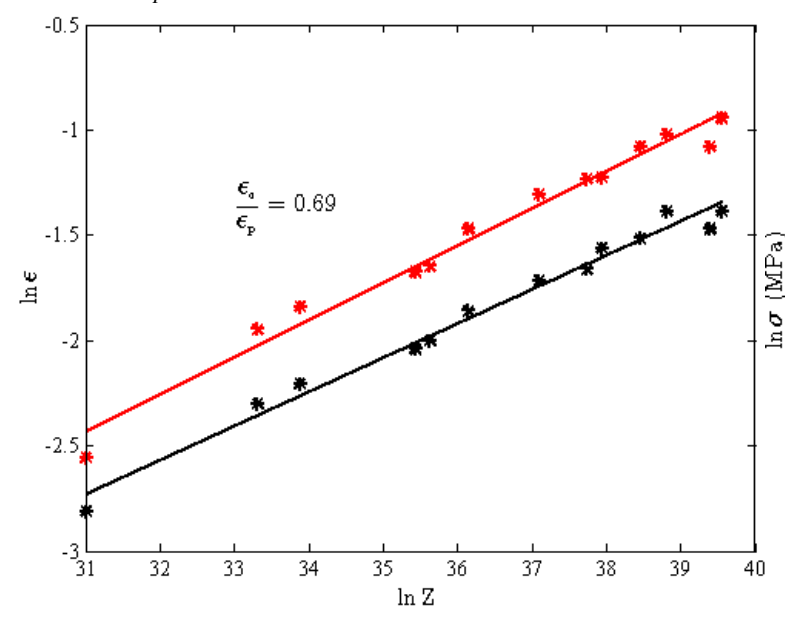

Figure 3.7: $\quad$ The relationship between $\epsilon_{c}$ and $\epsilon_{p}$ (left) and between $\sigma_{c}$ and $\sigma_{p}$ (right) as a function of $\operatorname{lnZ}$ for 321 stainless steel.

Similar analyses were performed for the 304 steel and the results are shown in

Figure 3.8: The relationship between $\epsilon_{c}$ and $\epsilon_{p}$ (left) and between $\sigma_{c}$ and $\sigma_{p}$ (right) as a function of $\ln Z$ for 304 stainless steel. 

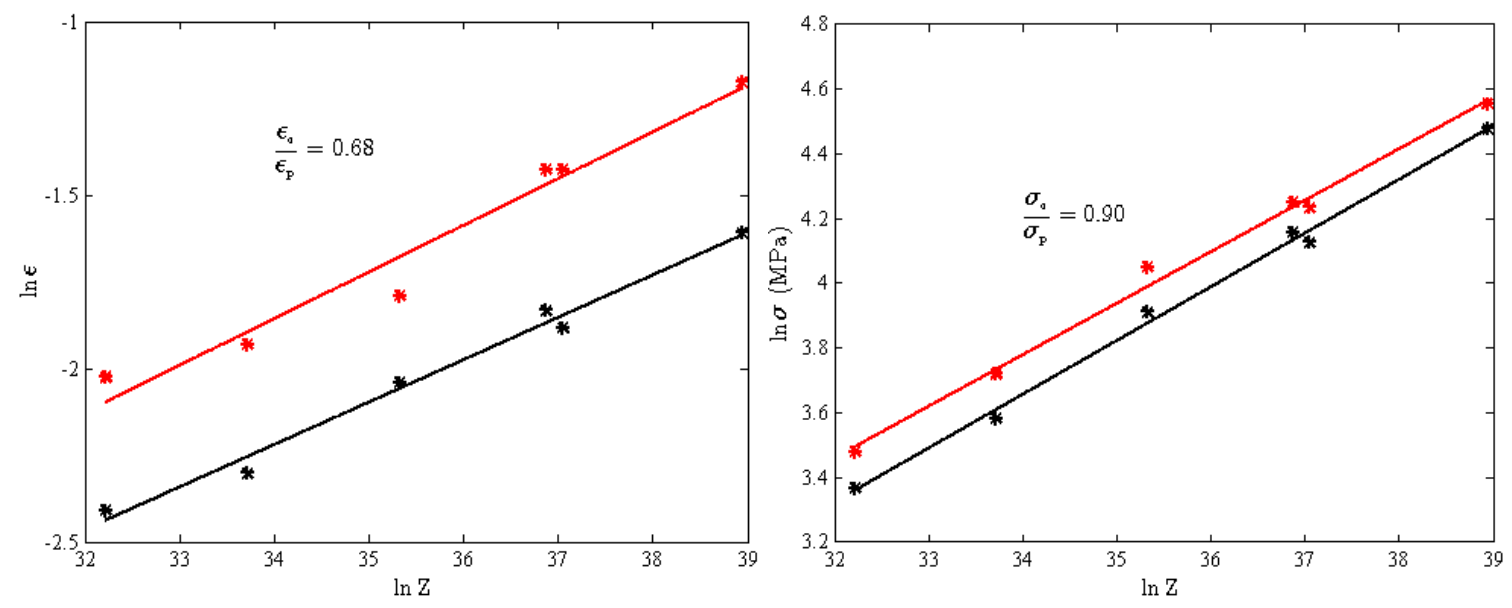

Figure 3.8: The relationship between $\epsilon_{c}$ and $\epsilon_{p}$ (left) and between $\sigma_{c}$ and $\sigma_{p}$ (right) as a function of $\ln \mathrm{Z}$ for 304 stainless steel.

Hence the following are the relationships for the critical strain and stress for 304 steel:

$$
\begin{aligned}
& \sigma_{c}=0.90 \sigma_{p} \\
& \epsilon_{c}=0.68 \epsilon_{p}
\end{aligned}
$$

These values are in good agreement with the literature [20][21] where it was pointed out that generally $\epsilon_{c} \approx(0.6-0.8) \epsilon_{p}$ for microalloyed and stainless steels.

\subsection{Summary of the characteristic constants}

The constants for the hyperbolic sine equation for hot working are summarised in table 3.2

Table 3.2: A summary of the characteristic constants.

\begin{tabular}{|ccc|}
\hline Constant & AISI 304 & AISI 321 \\
\hline$n^{\prime}$ & 8.66 & 8.77 \\
$\beta$ & 0.069 & 0.076 \\
$\alpha$ & 0.008 & 0.009 \\
$\mathrm{~A}_{3}$ & $2.14 \times 10^{17} \mathrm{MPa}^{-1} s^{-1}$ & $9.76 \times 10^{17} \mathrm{MPa}^{-1} s^{-1}$ \\
$\mathrm{~A}_{1} \mathrm{~d}_{\mathrm{o}}^{\mathrm{m}}$ & $1.8 \times 10^{-3}$ & $1.9 \times 10^{-3}$ \\
$\mathrm{Q}$ & $446 \mathrm{~kJ} / \mathrm{mol}$ & $465 \mathrm{~kJ} / \mathrm{mol}$ \\
$q$ & 0.13 & 0.13 \\
$n$ & 6.1 & 6.1 \\
$\sigma_{c}$ & $0.9 \sigma_{p}$ & $0.88 \sigma_{p}$ \\
$\epsilon_{c}$ & $0.68 \epsilon_{p}$ & $0.69 \epsilon_{p}$ \\
\hline
\end{tabular}




\subsection{Discussion}

The majority of the flow curves that showed the occurrence of DRX exhibited a single peak except the test that was deformed at $1200^{\circ} \mathrm{C}$ and a strain rate of $0.001 / \mathrm{s}$ which showed multiple peaks. These peaks were mainly visible when the deformation was at a high temperature and low strain rate combination. Multiple peaks can reportedly occur if $d_{o}>2 d_{\text {DRX }}$ where $d_{\text {DRX }}$ is the dynamically recrystallised grain size and $d_{o}$ is the initial grain size and this generally occurs at high temperatures and slow strain rates [22].

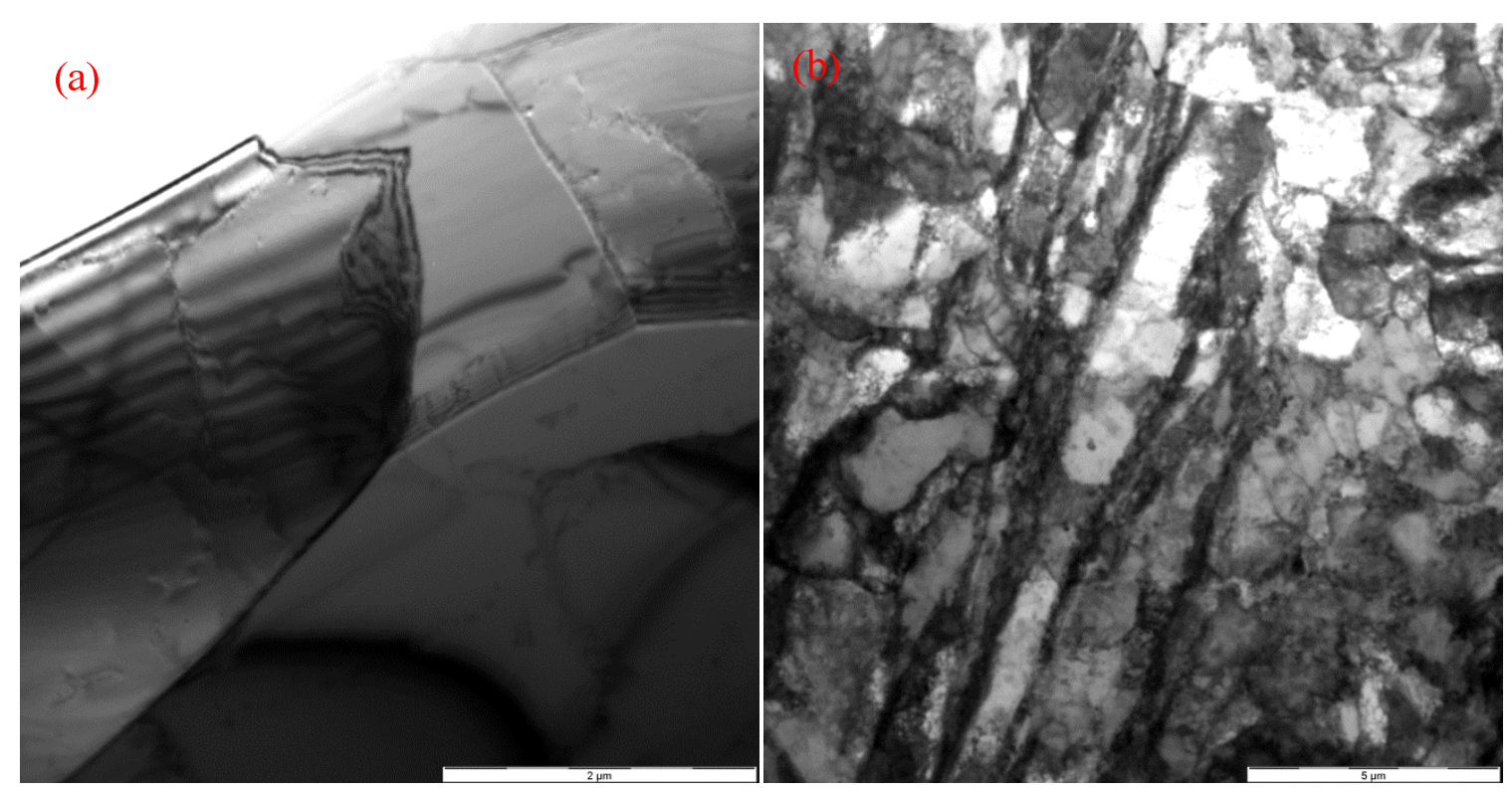

Figure 4.1: $\quad$ TEM micrographs of hot deformed 321 steel at a strain rate of 0.01 with (a) deformed at $1050^{\circ} \mathrm{C}$ and (b) deformed at $800^{\circ} \mathrm{C}$. Figure (a) is a dynamically recrystallised substructure while figure (d) shows the dislocation network

It is evident from the results presented that DRX takes place, as collaborated by Figure 4.1(a), under the deformation conditions where the critical $\ln Z$ value for both steels is about 41 (with $\mathrm{Z}$ in $s^{-1}$ ). Below this critical value, the operating softening mechanism is DRX while above this value, the dominant softening mechanism is $\mathrm{DRV}$. The $\mathrm{Z}$ parameter is related to the dislocation density through the flow stress or strain rate equations such as $\sigma=c \mathrm{G} b \sqrt{\mathrm{N}_{\mathrm{d}}}$ and 
$\dot{\epsilon}=b \mathrm{~N}_{\mathrm{d}} \bar{v} \quad$ where $\mathrm{c}$ is a constant of the order of $0.5[23], \mathrm{G}$ is the shear elastic modulus, $b$ is the burgers vector, $\mathrm{N}_{\mathrm{d}}$ is the dislocation density and $\bar{v}$ is the average mobile velocity while the rate of recovery is directly proportional to the dislocation density [24]. As the $\mathrm{Z}$ parameter increases (higher strain rate and lower deformation temperature), the dislocation density also increases and this causes the peak strain to rise until the critical value is reached as shown in figure 3.5(b) and (c). At this critical point, the subgrain structure reaches a steady state and the dislocation density remains constant [24]. The strength of the material is bound to increase because a larger stress will be required to move these dislocations through a matrix already containing many other dislocations. As seen in figure 3.5 , a further increase in the $\mathrm{Z}$ parameter has no influence on the peak strain because of the fact that the mobile dislocation density has reached a steady state. Finally, it was observed that at strain rates greater than $0.05 s^{-1}$, dynamic recovery DRV was dominant while increasing the DRX to DRV transition temperature to higher $\mathrm{Z}$ values.

\subsection{Marked differences between 321 and 304 steels}

The differences in hot working constants found between these two steels are most significant in the activation energies (465000 J/mol for 321 and $446000 \mathrm{~J} / \mathrm{mol}$ for 304) and the structure factors $\mathrm{A}_{3}\left(9.76 \times 10^{17} \mathrm{MPa}^{-1} s^{-1}\right.$ for 321 and $2.4 \times 10^{17} \mathrm{MPa}^{-1} s^{-1}$ for 304) while all other constants show relatively minor differences if at all. It can be seen from these results that the $A_{3}$ for 321 steel is about four times higher than the $A_{3}$ for 304 steel. Wherefrom do these differences arise and how significant are they in terms of hot working characteristics? Are they fundamentally different or are they caused by minor differences in chemical composition relevant only to these two steels? 
There are two scenarios that can affect dynamic recrystallisation which are firstly deformation conditions because it is a thermally activated process and secondly, the alloying elements. It can be seen in figure 3.2 that DRX can be retarded by either increasing the strain rate or by reducing the deformation temperature. But deformation conditions should not have an effect on the activation energy if the low stacking fault energies of both of these steels restrict cross slipping of screw dislocations during recovery which is then dominated by climb of edge dislocations. Work hardening behaviour of austenitic steels is related mainly to their stacking fault energy, (SFE) since the lower the SFE, the greater the work hardening. The SFE for 321 is about $20 \mathrm{~mJ} / \mathrm{m}^{2}$ while that of 304 is about $21 \mathrm{~mJ} / \mathrm{m}^{2} \quad$ [25][26] and these two materials are classified as low stacking fault energy steels. If DRX takes place by self-diffusion, DRV can only have the "same" Q if DRV occurs primarily by climb of edge dislocations and not by cross slipping of screw dislocations. The low SFE of about $20 \mathrm{~mJ} / \mathrm{m}^{2}$ will lead to widely extended dislocations which makes cross slipping very difficult.

On the other hand it is known that some alloying elements have retarding effects on DRX while others have retarding effects on DRV[27] and this makes it very difficult to say for certain the net effect of the alloying elements. The alloying elements may have an effect of solute drag on the movement of dislocations and grain boundary mobility which contributes to the ease of nucleating new grains. In this case, the contributions are potentially arising from the differences in concentration between the two steels in their solute content of $\mathrm{Cr}, \mathrm{Si}$, $\mathrm{Mn}, \mathrm{N}, \mathrm{Ti}, \mathrm{Al}$ and Ni. The effects of differences in $\mathrm{Cr}$ and $\mathrm{Ni}$ possibly cancel each other out as there is no significant net difference if the two are taken together. The nucleation rate of new DRX grains is inter alia a function of the rate of self-diffusion and the rate of nucleation, therefore, becomes lower with higher activation energy at constant temperatures. 
Furthermore, alloying elements also may have retarding effects on DRX by increasing the activation energy of deformation [28]. These are mainly the alloying elements that have a similar atomic radius with $\mathrm{Fe}$ such as $\mathrm{Cr}, \mathrm{Mn}, \mathrm{Si}, \mathrm{Al}$, Ni etc. which occupy substitutional sites in austenite. Retardation of DRX comes from the effect of solute particles that provide solute drag which affects the mobility of the migrating grain boundaries.

Those elements that occupy interstitial sites, however, have a tendency to lower the activation energy and this accelerates the initiation of dynamic recrystallisation [29][30]. This was confirmed in this study, for instance at a value of $Z=40$ in figure 3.5, the critical strain $\varepsilon_{\mathrm{c}}$ for DRX in steel 304 was found to be 0.24 while that for the steel 321 at the same value of $\mathrm{Z}$ was 0.31. The $\mathrm{N}$ and $\mathrm{C}$ are in solution during hot working in the steel 304 thereby has accelerated the onset of DRX if compared to steel 321 where the $\mathrm{N}$ and $\mathrm{C}$ is bound within the $\operatorname{Ti}(\mathrm{CN})$. Concerning the differences in activation energy, it has been found by McQueen and coworkers[10] that the peak strain, flow stress and activation energy can be raised by the amount of retained $\delta$-ferrite present in the matrix, which was higher in the as-received 321 steel than in the 304 steel. It is also mentioned that the amount of high temperature carbides and carbonitrides such as $\mathrm{Ti}(\mathrm{CN}) / \mathrm{TiC}$ can raise the activation energy of hot working mainly because the carbon and nitrogen which are responsible for reducing Q are tied up. This can be verified by the two steels under study in that Q is lower in 304 steel because it has free nitrogen and carbon in solution as compared to 321 steel which has carbon and nitrogen tied up by titanium. Chromium and titanium have the tendency to promote $\delta$-ferrite formation and it is suggested that in order to avert this, nickel additions should be increased as the presence of $\delta$-ferrite greatly impairs the hot workability of steels and the strength of austenite[2]. However the contributions of other alloying elements should be taken into account depending upon whether they are austenite or ferrite formers as they will have a positive or negative 
effect on the $\delta$ - ferrite formation. The adverse effect of $\delta$-ferrite in hot working is attributed to a maximum $\alpha-\gamma$ interfacial area at which voids may nucleate[2].

Others [10][31] have shown that $\mathrm{Q}$ is generally a function of the chemical composition of the alloy and that it generally increases with alloy content save for carbon and nitrogen. Since $n$ is the same for both steels under study, the change in $\mathrm{A}_{3}$ can be said to come partly from the change in $\mathrm{Q}$ which is affected by parameters such as the chemical composition, the dislocation density, the grain size, the delta-ferrite content and other microstructural features. This may be seen in figure 3.5(a)'s intercept, which represents " $\ln \mathrm{A}_{3}$ " as it means that a change in $\mathrm{Q}$ pushes the regression line up or down hence the value for $A_{3}$ will be higher or lower if strain rate is kept constant. The general observation from the literature [6] on the structure factor $\mathrm{A}_{3}$ of steels is that it is proportional to the activation energy of hot working, i.e. when $\mathrm{Q}$ is high, $\mathrm{A}_{3}$ is also high and it is also a function of the chemistry of the material and other factors as pointed out before. This can be collaborated by the findings of Medina and Hernandez[31] who studied a number of materials and came to the same conclusion. Therefore, $\mathrm{A}_{3}$ as a constant has no simple physical meaning[32] but it is a function of the strain rate, the activation energy and the stress exponent $n$ as seen in figure 3.5(a) but as the name suggests, $A_{3}$ is also a function of the structure of the material itself. Therefore, it can be concluded from the results obtained in this study that this observation is also obeyed qualitatively.

No direct correlation has been observed between $\alpha$ and $\mathrm{Q}$ from the literature and neither can it be related to the chemistry but it has been stated to be material specific [33]. Finally, it was found that the values of $n^{\prime}$ increased with a decrease in deformation temperature, 
confirming that the power law breaks down, resulting in an increase in flow stress. This is clearly seen from figure 3.3(a) in that the lines are not necessarily parallel to each other, particularly at the two extremes of test temperatures. Overall, therefore, the results presented in table 3.2 are in general agreement with what is reported in the literature [34][35][10] and more specifically in agreement with what others have found in austenitic stainless steels [33].

The values for $\mathrm{Q}, \mathrm{A}_{3}, \alpha$, and $n$ from table 3.2 will enable one to predict the maximum deformation resistance during hot rolling to be expected through the temperature compensated strain rate parameter $\mathrm{Z}$ for these materials. Hence the final $\mathrm{Z}$ parameters for the two steels can indeed now be written as:

$$
\begin{aligned}
& Z_{304}=\dot{\epsilon} \exp \left(\frac{446000}{8.314 T_{d}}\right)=2.14 \times 10^{17} \times\left[\sinh \left(0.008 \sigma_{p}\right)\right]^{6.1} \\
& Z_{321}=\dot{\epsilon} \exp \left(\frac{465000}{8.314 T_{d}}\right)=9.76 \times 10^{17} \times\left[\sinh \left(0.009 \sigma_{p}\right)\right]^{6.1}
\end{aligned}
$$

Given the same deformation conditions (e.g. same strain rate and same deformation temperature), it is evident from equation [4-1] and [4-2] that the $\mathrm{Z}$ parameter for 304 will be slightly lower than that of the 321 steel. This is collaborated by figure 4.2 that if the same $\mathrm{Z}$ value is considered, the deformation stress values for the 304 steel will be higher than the equivalent values for the 321 steel. As may be seen from figure 3.5, increasing the $\mathrm{Z}$ value increases the stress and strain for the initiation of DRX. Conversely, when the $\mathrm{Z}$ value is low, the rate of softening becomes higher.

\subsection{Comparison of the flow curves}

The differences in the flow curves can be accounted for by using equation [3-5] by making $\sigma$ the subject of the formula of which the final expression becomes: 
$\sigma=\frac{1}{\alpha} \sinh ^{-1}\left[\frac{1}{\mathrm{~A}_{3}} \dot{\epsilon} \exp \left(\frac{\mathrm{Q}}{\mathrm{RT}_{\mathrm{d}}}\right)\right]^{1 / n}$

From this equation, it can be seen that the major contribution to differences in the flow stress curves comes from $\alpha, \mathrm{Q}$, and $\mathrm{A}_{3}$. It was also observed in the flow curve profiles that showed characteristics of a DRX mechanism, that the peak strain for 304 is lower than that of 321 under DRX conditions.

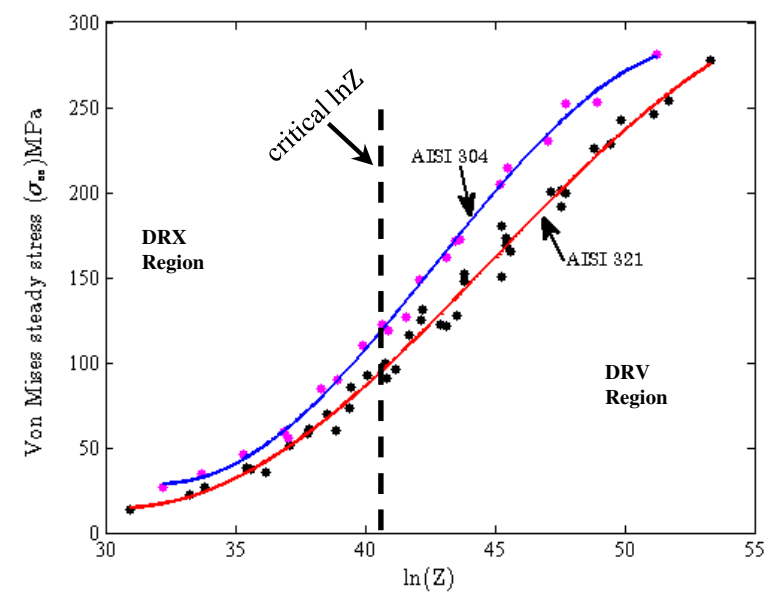

Figure 4.2: $\quad$ Comparison of flow stress profiles of 321 and 304 as a function of $\ln Z$.

Figure 4.2 shows that if the same $\mathrm{Z}$ is used for scheduling these two materials under study 321 steel will always be softer as compared to 304 steel, both within the DRV and the DRX regions and it is, therefore, expected that the hot rolling mill loads of 304 will be higher than for 321 at equivalent $\mathrm{Z}$ values. Should equivalent flow stresses be required, however, the hot rolling conditions in terms of $\mathrm{Z}$ of 321 would have to be adjusted to a higher value than for 304.

\subsection{Conclusions}

The hot working characteristics of 321 steel and 304 steel under study in this paper over a temperature range of $800-1200^{\circ} \mathrm{C}$ and over a strain rate of $0.001-5 / \mathrm{s}$ have shown the following conclusions: 
1. The difference in hot working flow stress arises from differences in $\mathrm{A}_{3}, \mathrm{Q}, \delta$ - ferrite content, free nitrogen and free carbon. The three parameters $\left(\mathrm{A}_{3}, \mathrm{Q}, \delta\right.$ - ferrite $)$ are interlinked in that they affect each other. The increase in $\delta$ - ferrite as was found in the steel 321, will increase the activation energy Q which in effect will also contribute to an increase in $\mathrm{A}_{3}$. The objective in 321 stainless steels, should therefore, be to lower the $\delta$ - ferrite content by adjusting the content of austenite formers because of the loss of the $\mathrm{C}$ and $\mathrm{N}$ in solution, as the $\delta$-ferrite has a detrimental effect on hot workability of steels.

2. The critical stress and strain conditions for the initiation of dynamic recrystallisation were found to be; $\sigma_{c}=0.88 \sigma_{p}$ and $\epsilon_{c}=0.69 \epsilon_{p}$ for steel 321 and $\sigma_{c}=0.90 \sigma_{p}$ and $\epsilon_{c}=0.68 \epsilon_{p}$ for steel 304;

3. The hot working activation energy for steel 321 is significantly higher than that for 304 at $465 \mathrm{~kJ} / \mathrm{mol}$ and $446 \mathrm{~kJ} / \mathrm{mol}$ respectively which affects their respective $\mathrm{Z}$ parameters at otherwise equivalent conditions.

4. The material structure factors for 321 and 304 steels are $9.76 \times 10^{17} \mathrm{MPa}^{-1} s^{-1}$ and $2.14 \times 10^{17} \mathrm{MPa}^{-1} s^{-1}$

5. For the optimisation of hot working of the 321 steel, a different rolling schedule at slightly higher $\mathrm{Z}$ values than for the steel 304 may be adopted to achieve equivalence in the mill loads.

6. To improve the room temperature proof stress of 321 steel, the following are suggested: when rolling, the $\mathrm{Z}$ value must be high enough to target the DRV region and secondly, consideration should be given to change the chemistry of 321 steel to achieve a low delta ferrite content. 
7. The critical $\ln Z$ value for the transition from dynamic recrystallisation to dynamic recovery is about 41 (with $\mathrm{Z}$ in $\mathrm{s}^{-1}$ ) for both steels.

\subsection{References}

[1] V. Moura, A. Y. Kina, S. S. M. Tavares, L. D. Lima, and F. B. Mainier, "Influence of stabilization heat treatments on microstructure, hardness and intergranular corrosion resistance of the AISI 321 stainless steel.PDF," Journal of Materials Science, vol. 43, pp. 536-540, 2008.

[2] F. B. Pickering, Physical Metallurgy And The Design Of Steels, 1st Editio. Applied Science Publishers, 1978.

[3] W. Stumpf, "Grain size modelling of a low carbon strip steel during hot rolling in a Compact Strip Production ( CSP ) plant using the Hot Charge Route," The Journal of South African Institute of Mining and Metallurgy, vol. 103, no. 10, pp. 617-632, 2003.

[4] G. E. Dieter, H. A. Kuhn, and S. L. Semiatin, Eds., Handbook of Workability and Process Design. ASM International, 2003, p. 48,63.

[5] J. L. Uvira, "Hot Compression of ARMCO Iron and Silicon Steel," McGill University, 1969.

[6] H. J. Mcqueen and N. D. Ryan, "Constitutive analysis in hot working," Materials Science and Engineering A, vol. 322, pp. 43 - 63, 2002.

[7] R. D. Doherty et al., "Current issues in recrystallization: a review," Materials Science and Engineering A, vol. 238, pp. 219-274, Nov. 1997.

[8] H. J. Mcqueen, "Development of dynamic recrystallization theory," Materials Science and Engineering A, vol. 389, pp. 203-208, 2004. 
[9] H. J. Mcqueen and W. Blum, "Dynamic recovery: sufficient mechanism in the hot deformation of Al (<99.99)," Materials Science and Engineering A, vol. 290, pp. 95 $107,2000$.

[10] H. J. Mcqueen, S. Yue, N. D. Ryan, and E. Fry, "Hot Working Characteristics Of Steels In Austenitic State," Journal of Materials Processing Technology, vol. 53, pp. 293-310, 1995.

[11] H. J. Mcqueen and J. J. Jonas, "Recent Advances in Hot Working: Fundamental Dynamic Softening Mechanisms," Journal of Applied Metalworking, vol. 3, no. 3, pp. 233-241, 1984.

[12] C. M. Sellars, "Computer Modelling of Hot Working Processes," Materials Science and Technology, vol. 1, pp. 325-332, 1985.

[13] P. L. Orsetti and C. M. Sellars, "Quantitative Metallography of Recrystallization," Acta Metallurgica, vol. 45, no. 1, pp. 137-148, 1997.

[14] C. M. M. Sellars, "The physical metallurgy of hot working," Hot Working and Forming Processes, vol. B35, pp. 3-16, 1980.

[15] M. Shaban and B. Eghbali, "Determination of critical conditions for dynamic recrystallization of a microalloyed steel," Materials Science \& Engineering A, vol. 527, no. 16-17, pp. 4320-4325, 2010.

[16] H. Wu, L. Du, and X. Liu, "Dynamic Recrystallization and Precipitation Behavior of Mn - Cu - V Weathering Steel," Journal of Materials Science \& Technology, vol. 27, no. 12, pp. 1131-1138, 2011.

[17] C. Roucoules, P. D. Hodgson, S. Yue, and J. J. Jonas, "Softening and Microstructural Change Following the Dynamic Recrystallization of Austenite," Metallurgical and Materials Transactions A, vol. 25, pp. 389-400, 1994. 
[18] M. Jafari, A. Najafizadeh, and J. Rasti, "Dynamic Recrystallization by Necklace Mechanism During Hot Deformation of 316 Stainless Steel," International Journal of Iron \& Steel Society of Iran, vol. 4, pp. 16-23, 2007.

[19] J. J. Jonas, X. Quelennec, L. Jiang, and E. Martin, "The Avrami kinetics of dynamic recrystallization," Acta Materialia, vol. 57, pp. 2748-2756, 2009.

[20] H. Keshmiri and G. R. Ebrahimi, "Dynamic recrystallization behavior of superaustenitic stainless steel containing of $16 \% \mathrm{Cr}$ and $25 \% \mathrm{Ni}$," in 11th Iranian Conference on Manufacturing Engineering, 2010.

[21] S. Cho and Y. Yoo, "Hot rolling simulations of austenitic stainless steel," Materials Science, vol. 36, pp. 4267 - 4272, 2001.

[22] A. Dehghan-Manshadi and P. D. Hodgson, "Dynamic recrystallization of austenitic stainless steel under multiple peak flow behaviours," ISIJ International, vol. 47, no. 12, pp. 1799-1803, 2007.

[23] W. Stumpf, "Hot work modelling of two equivalent low carbon strip steels produced, respectively, by the cold charge route and by the hot charge route," Journal of South African Institute of Mining and Metallurgy, vol. 104, no. 11, pp. 643-652, 2004.

[24] F. J. Humphreys and M. Hatherly, Recrystallization And related Annealing Phenomena, 2nd Editio. Elsevier Ltd, 2004, p. 17.

[25] W. Zhang, J. Wu, Y. Wen, J. Ye, and N. Li, "Characterization of different work hardening behavior in AISI 321 stainless steel and Hadfield steel," Journal of Materials Science, vol. 45, no. 13, pp. 3433-3437, Mar. 2010.

[26] M. A. Meyers, Y. B. Xu, Q. Xue, M. T. Pérez-Prado, and T. R. McNelley, "Microstructural evolution in adiabatic shear localization in stainless steel," Acta Materialia, vol. 51, pp. 1307-1325, Mar. 2003. 
[27] A. I. Fernández, P. Uranga, and B. López, "Dynamic recrystallization behavior covering a wide austenite grain size range in $\mathrm{Nb}$ and $\mathrm{Nb}$ - Ti microalloyed steels," Materials Science, vol. 361, pp. 367-376, 2003.

[28] S. Bao, G. Zhao, C. Yu, Q. Chang, C. Ye, and X. Mao, "Recrystallization behavior of a Nb-microalloyed steel during hot compression," Applied Mathematical Modelling, vol. 35, pp. 3268-3275, 2011.

[29] E. Lopez-Chipres, I. Mejia, C. Maldonado, A. Bedolla-Jacuinde, and J. M. Cabrera, "Hot ductility behavior of boron microalloyed steels," Materials Science and Engineering A, vol. 460-461, pp. 464-470, 2007.

[30] L. Liang-yun, Q. Chun-lin, Z. De-wen, G. Xiu-hua, and D. Lin-xiu, "Dynamic and Static Recrystallization Behavior of Low Carbon High Niobium Microalloyed Steel," Journal of Iron and Steel Research International, vol. 18, no. 1, pp. 55-60, 2011.

[31] S. F. Medina and C. A. Hernandez, "General Expression Of The Zener-Hollomon Parameter As A Function Of The Chemical Composition Of Low Alloy And Microalloyed Steels," Acta Metallurgica, vol. 44, no. 1, pp. 137-148, 1996.

[32] K. P. Rao and Y. V. R. K. Prasad, "High temperature deformation kinetics of Al4Mg alloy," Journal of Mechanical Working Technology, vol. 13, pp. 83-95, 1986.

[33] W. Stumpf, "Hot working of low carbon strip steels : are the constitutive constants universal for this class of alloy or are they material specific?," South African Journal of Science, vol. 102, no. 11/12, pp. 565-571, 2006.

[34] A. Dehghan-Manshadi, M. R. Barnett, and P. D. Hodgson, "Recrystallization in AISI 304 austenitic stainless steel during and after hot deformation," Materials Science and Engineering A, vol. 485, pp. 664-672, 2008. 
[35] B. Verlinden, J. Driver, I. Samajdar, and R. D. Doherty, Thermo-Mechanical Processing of Metallic Materials, 1st Editio. Elsevier, 2007. 